\title{
Density Functional Calculations of Small Anionic Clusters of Group III Nitrides
}

\author{
Aurora Costales* and Ravindra Pandey \\ Department of Physics, Michigan Technological University, Houghton, Michigan 49931 \\ Received: October 8, 2002
}

\begin{abstract}
In this paper, we study the changes in the structural, vibrational, bonding, and electronic properties of small clusters of the group III nitrides when an electron is added to the neutral clusters. The results, based on density functional calculations, reveal that the addition of an electron induces significant structural changes in the neutral cluster configurations. The atomic charge analysis suggests that the added electron is located over the metallic atoms in dimers and trimers and equally shared by metal and nitrogen atoms in monomers. The calculated electron affinity values depend on both the cations and the structural configuration in these clusters.
\end{abstract}

\section{Introduction}

The semiconductor materials industry has uninterruptedly grown during the past decades. After extensive use of the electronic properties of silicon over almost 40 years, the need for new materials with much shorter commutation times or better optoelectronic properties has drawn increasing attention to the III-V binary semiconductors. Because of its greater similarity with $\mathrm{Si}, \mathrm{GaAs}$ has received the most attention (see ref 1 and references therein). Recently, the focus has shifted to compounds such as $\mathrm{AlN}$, GaN, and $\mathrm{InN}$ with greater electronegativity differences. The electronic properties of the group III nitrides make them suitable for the fabrication of light-emitting diodes and a new generation of short-wavelength lasers. They also have multiple applications as microelectronic elements in hightemperature and high-power electronic devices. ${ }^{2}$ Representing a link between the isolated molecular world and the solid state, the study of these clusters with different sizes has drawn increasing attention during the last few years; this attention was mainly focused on $\mathrm{Al}_{x} \mathrm{~N}_{y}{ }^{3-12}$ A few studies were also carried out on $\mathrm{Ga}_{x} \mathrm{~N}_{y}$ and $\mathrm{In}_{x} \mathrm{~N}_{y}{ }^{8-11,13}$ Recent experimental studies on gaseous AlN using infrared spectroscopy and the Knudsen cell mass showed the existence of a large diversity of neutral and charged species. ${ }^{7,14,15}$ In addition, photoelectron spectroscopy experiments ${ }^{16-19}$ and their theoretical analysis ${ }^{20-22}$ were reported for $\mathrm{Al}_{x} \mathrm{P}_{y}, \mathrm{Ga}_{x} \mathrm{P}_{y}$, and $\mathrm{In}_{x} \mathrm{P}_{y}$. In these experiments, the photodetachment of an electron from anions was the source of the information about the cluster's electronic structure. The cluster configurations obtained by density functional calculations together with the calculated vibrational frequencies were used to interpret the experimental results.

The aim of this work is to analyze the changes in the structural, vibrational, electronic, and bonding properties of group III nitride small clusters $(n=1,2,3)$ upon the accommodation of an extra electron. We begin with the configurations of neutral group III nitride monomers, dimers, and trimers, which were obtained ${ }^{8,9}$ using the DMol program. ${ }^{23}$ This code employs double- $\zeta$ numerical basis sets with polarization functions (DNP). However, these basis sets are not flexible enough to describe the negatively charged clusters. This

* Corresponding author. E-mail: mcostale@mtu.edu. Permanent address: Departamento de Química Física y Analítica, Facultad de Química, Universidad de Oviedo, 33006-Oviedo, Spain deficiency of the DNP basis sets led us to use Gaussian basis sets since analytical basis sets can provide a larger flexibility to describe the anionic clusters. For the present work, we use the Gaussian 98 code $^{24}$ to perform total energy calculations, employing the same theoretical framework. ${ }^{8}$ The neutral cluster configurations are also calculated for a better comparison with the results on anionic clusters. For the neutral clusters, the Gaussian results are in agreement with the DMol results except for one case that we will discuss.

We have organized the rest of the paper as follows. In section II, details of the computational techniques employed in this study are given. The results are presented and discussed in section III. Finally, we will give a summary of the results of this work in section IV.

\section{Computational Method}

The electronic structure calculations were performed on several neutral and anionic structural isomers of $(\mathrm{MN})_{n}(\mathrm{M}: \mathrm{Al}$, $\mathrm{Ga}$, and In; $n=1-3$ ) clusters using the Gaussian 98 code. $^{24}$ All calculations were carried out by solving the Kohn-Sham equations in the framework of the density functional theory (DFT). We have employed the generalized gradient approximation (GGA) using the functionals of Becke ${ }^{25}$ and Perdew and $\mathrm{Wang}^{26}$ to represent the exchange and correlation contributions, respectively (BPW91). The choice of the theoretical framework is based on previous studies (see ref 8). We have used 6-31G** basis sets for $\mathrm{Al}, \mathrm{Ga}$, and $\mathrm{N}$. For the In atom, we have used a double- $\zeta$ valence plus polarization (DZVP) basis set optimized for the density functional theory orbitals. ${ }^{27}$ The inclusion of the diffuse functions in the basis sets $\left(6-31+\mathrm{G}^{* *}\right)$ has been analyzed: the variation in equilibrium distances and dissociation energies with respect to the $6-31 G^{* *}$-based results reported here is smaller than $1 \%$ both for neutral and anionic monomers. Both neutral and anionic monomer frequencies decrease by about $2 \%$. Bader's atomic charges are larger by 3\% (neutral) and 5\% (anion) when using diffuse functions. Errors of $0.03 e$ and $0.08 e$ in the charge transfer are quite small and certainly do not change the qualitative picture of the charge distribution. These results and our aim of comparing with the previous results on the same footing led us to use the $6-31 \mathrm{G}^{* *}$ basis set.

All of the structures studied in this work have been fully optimized by employing the gradient and updated Hessian. The 
TABLE 1: Electronic States, Bond Lengths, Dissociation Energies, and Vibrational Frequencies for Neutral and Anionic Monomers

\begin{tabular}{lcccc}
\hline & ${ }^{2 \mathrm{~S}+1} \Lambda$ & $R_{\mathrm{e}}(\AA)$ & $\Delta D_{\mathrm{e}}(\mathrm{eV})$ & $\omega_{\mathrm{e}}\left(\mathrm{cm}^{-1}\right)$ \\
\hline $\mathrm{AlN}$ & ${ }^{3} \Pi$ & 1.80 & 2.76 & 749 \\
$\mathrm{AlN}^{-}$ & ${ }^{2} \Sigma$ & 1.73 & 4.28 & 882 \\
$\mathrm{GaN}^{3} \Pi$ & 1.87 & 2.24 & 595 \\
$\mathrm{GaN}^{-}$ & ${ }^{2} \Sigma$ & 1.76 & 4.06 & 752 \\
$\mathrm{InN}$ & ${ }^{3} \Sigma$ & 2.27 & 1.99 & 418 \\
$\mathrm{InN}^{-}$ & ${ }^{2} \Sigma$ & 2.08 & 2.78 & 560
\end{tabular}

convergence criteria were employed for the gradient $10^{-4}$ hartree/ $\AA$ and for the energy $10^{-9}$ hartree. For the lowest energy isomer in the neutral and anionic clusters, the vibrational frequencies were computed under the harmonic approximation. The force constants have been computed analytically. The atomic properties of the most stable isomers have been studied under the atoms in molecules theory (AIM) ${ }^{28}$ using the AIMPAC95 package. ${ }^{29}$ To integrate the atomic properties, we used the Promega algorithm. The error in the total charge is less than $10^{-3} e$.

\section{Results and Discussion}

A. Structural and Vibrational Properties: Monomers. The geometrical parameters together with the electronic spin states and the dissociation energy for the neutral and anionic monomers are collected in Table 1 . The dissociation energies are computed with respect to the atoms in their ground states using the same DFT-BPW91 method, the negative charge being assigned to the metallic atom in the anionic monomer dissociation. For the neutral monomers, it is found that the ground electronic state is ${ }^{3} \Pi\left(\pi^{3} \sigma^{1}\right)$ for AlN and GaN and ${ }^{3} \Sigma\left(\pi^{2} \sigma^{2}\right)$ for InN. However, when an electron is added, the electronic state changes to ${ }^{2} \Sigma\left(\pi^{4} \sigma^{1}\right)$ in all cases. The trends observed in both neutral and anionic monomers in going from AlN to GaN to InN show an increase in the bond length, a decrease in the dissociation energy, and a decrease in the vibrational frequencies. These trends can easily be attributed to a weakening of the chemical bond between the metallic atom and the nitrogen in this series. Our results for $\mathrm{AlN}$ and $\mathrm{AlN}^{-}$are in good agreement with the available theoretical results. ${ }^{15,30}$ For GaN, we have found a different ground electronic state with respect to our previous results ${ }^{8}$ using the DMol program. The results for AlN and GaN are also in agreement with the data reported by Zhou et al. ${ }^{13}$ However, these authors predict the ground electronic state for the neutral $\mathrm{InN}$ to be ${ }^{3} \Pi$ in the B3LYP and BP96 frameworks, whereas in our calculations the ground electronic state is predicted to be ${ }^{3} \Sigma$, which is $0.20 \mathrm{eV}$ more stable than the ${ }^{3} \Pi$ state.

The addition of an electron to the neutral monomers results in a shortening of the bond length along with an increase in the vibrational frequency. This fact can be explained using the molecular orbital description of the monomer in which the added electron occupies a bonding orbital in the anionic configuration, thereby making anions more stable relative to neutral monomers. It is also reflected in the increase of the dissociation energy in going from the neutral to anionic monomers.

B. Structural and Vibrational Properties: Dimers. Figure 1 presents a schematic picture of the different isomers considered in this study. The choice of these isomers is based on our previous analysis on group III nitride clusters. ${ }^{8,9}$ The optimal values of bond lengths and the energies relative to the most stable isomer are collected in Table 2. The neutral linear dimers are found to be in a triplet electronic state, whereas a singlet state is predicted for the neutral rhombus isomer. All anionic clusters are found to be in a doublet electronic state.

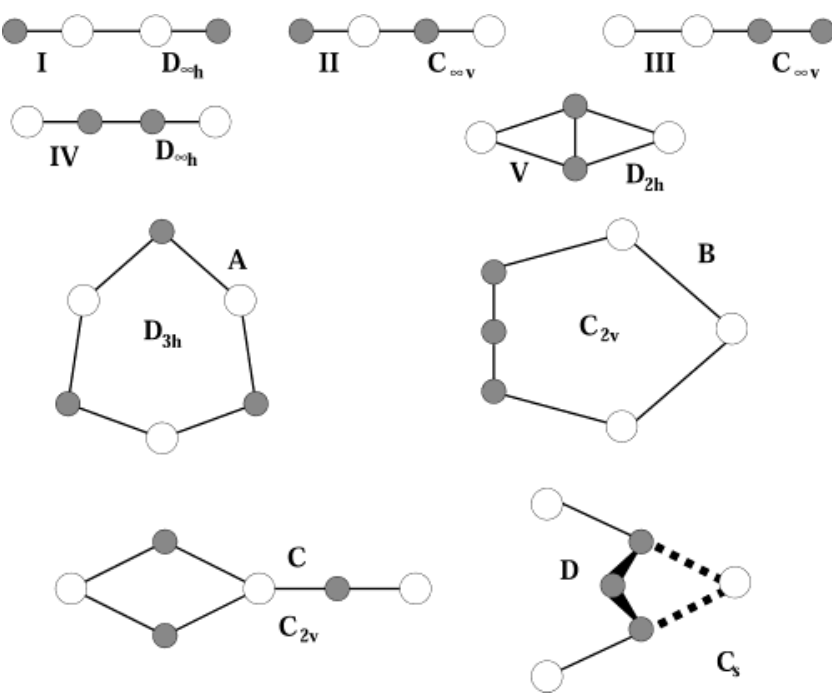

Figure 1. Schematic representation of some of the structures of dimers and trimers that were studied. The filled circles represent the nitrogen atoms, and the empty circles represent the metallic atoms.

TABLE 2: Symmetry, Bond Lengths $(\AA)$, and Energies Relative to the Most Stable Isomer for Each Isomer of the Dimers

\begin{tabular}{|c|c|c|c|c|c|}
\hline & symmetry & $R_{\mathrm{M}-\mathrm{N}}$ & $R_{\mathrm{N}-\mathrm{N}}$ & $R_{\mathrm{M}-\mathrm{M}}$ & $E(\mathrm{eV})$ \\
\hline \multicolumn{6}{|l|}{$\mathrm{Al}_{2} \mathrm{~N}_{2}$} \\
\hline & $\mathrm{I}-D_{\infty} h$ & 1.79 & & 2.50 & 5.38 \\
\hline & $\mathrm{II}^{a}-C_{\infty} v$ & $1.81,1.71,1.87$ & & & 2.46 \\
\hline & $\mathrm{III}^{a}-C_{\infty} v$ & 1.95 & 1.15 & 2.63 & 0.58 \\
\hline & IV- $D_{\infty h}$ & 1.89 & 1.21 & & 0.10 \\
\hline & $\mathrm{V}-D_{2 h}$ & 2.06 & 1.28 & 3.92 & 0.00 \\
\hline \multicolumn{6}{|l|}{$\mathrm{Al}_{2} \mathrm{~N}_{2}^{-}$} \\
\hline & $\mathrm{I}-D_{\infty h}$ & 1.75 & & 2.53 & 3.82 \\
\hline & II $-C_{\infty} v$ & $1.75,1.74,1.78$ & & & 1.24 \\
\hline & $\mathrm{IIII}^{a}-C_{\infty} v$ & 1.92 & 1.17 & 2.55 & 0.69 \\
\hline & IV- $D_{\infty h}$ & 1.82 & 1.23 & & 0.00 \\
\hline & $\mathrm{V}-D_{2 h}$ & 1.92 & 1.50 & 3.54 & 0.23 \\
\hline \multicolumn{6}{|l|}{$\mathrm{Ga}_{2} \mathrm{~N}_{2}$} \\
\hline & $\mathrm{I}-D_{\infty h}$ & 1.79 & & 2.27 & 4.86 \\
\hline & II $-C_{\infty} v$ & $1.88,1.72,1.86$ & & & 2.77 \\
\hline & $\mathrm{III}^{a, b}-C_{\infty} v$ & 4.69 & 1.16 & 2.68 & 0.16 \\
\hline & IV $-D_{\infty h}$ & 2.00 & 1.20 & & 0.00 \\
\hline & $\mathrm{V}-D_{2 h}$ & 2.16 & 1.26 & 4.14 & 0.01 \\
\hline \multicolumn{6}{|l|}{$\mathrm{Ga}_{2} \mathrm{~N}^{-}$} \\
\hline & $\mathrm{I}-D_{\infty h}$ & 1.76 & & 2.30 & 3.17 \\
\hline & II- $C_{\infty} v$ & $1.80,1.77,1.80$ & & & 1.55 \\
\hline & III- $C_{\infty} v$ & 1.99 & 1.16 & 2.37 & 0.00 \\
\hline & IV- $D_{\infty h}$ & 1.91 & 1.22 & & 0.06 \\
\hline & $\mathrm{V}^{a}-D_{2 h}$ & 2.19 & 1.25 & 4.21 & 0.91 \\
\hline \multicolumn{6}{|l|}{$\mathrm{In}_{2} \mathrm{~N}_{2}$} \\
\hline & $\mathrm{I}-D_{\infty h}$ & 2.02 & & 2.72 & 6.15 \\
\hline & $\mathrm{II}^{a}-C_{\infty} v$ & $2.10,1.95,2.08$ & & & 4.06 \\
\hline & $\mathrm{III}^{a, b}-C_{\infty} v$ & 3.57 & 1.12 & 2.84 & -0.32 \\
\hline & IV $-D_{\infty h}$ & 2.31 & 1.18 & & 0.001 \\
\hline & $\mathrm{V}-D_{2 h}$ & 2.44 & 1.24 & 4.73 & 0.00 \\
\hline \multicolumn{6}{|l|}{$\mathrm{In}_{2} \mathrm{~N}_{2}^{-}$} \\
\hline & $\mathrm{I}-D_{\infty h}$ & 1.98 & & 2.76 & 4.48 \\
\hline & $\mathrm{II}^{a}-C_{\infty} v$ & $2.02,1.99,2.02$ & & & 2.89 \\
\hline & $\mathrm{III}^{a, b}{ }_{-} C_{\infty} v$ & 5.28 & 1.12 & 2.93 & -0.59 \\
\hline & IV- $D_{\infty h}$ & 2.25 & 1.19 & & 0.00 \\
\hline & $\mathrm{V}-D_{2 h}$ & 2.51 & 1.22 & 4.87 & 0.40 \\
\hline
\end{tabular}

${ }^{a}$ Configurations with an imaginary frequency. ${ }^{b}$ Nonconnected cluster.

The lower energy isomers are found to be those (i.e., isomers III, IV, and V) in which $\mathrm{N}-\mathrm{N}$ bonds are present. They are nearly degenerate in energy. When the energy difference is less than 
$0.1 \mathrm{eV}$, the relative ordering may change if the level of theory or the basis sets are changed. Even so, the close values in energy give a cluster distribution in which both clusters will have almost the same weight. The $\mathrm{N}-\mathrm{M}-\mathrm{M}-\mathrm{N}$ isomer is always the least stable for all of the cases, followed by $\mathrm{M}-\mathrm{N}-\mathrm{M}-\mathrm{N}$ isomer. This ordering of isomers is a consequence of the number and type of bonds exhibited in each structure, suggesting that the $\mathrm{M}-\mathrm{M}$ bond is weaker than both the $\mathrm{N}-\mathrm{N}$ and $\mathrm{M}-\mathrm{N}$ bonds.

The optimized configurations of $\mathrm{Ga}-\mathrm{Ga}-\mathrm{N}-\mathrm{N}$ and $\mathrm{In}-\mathrm{In}-$ $\mathrm{N}-\mathrm{N}$ seem to represent the case of a metal diatomic molecule weakly bonded to $\mathrm{N}_{2}$ with a metal-nitrogen bond distance of $4.7 \AA$ or $3.6 \AA$, respectively. In this way, we can consider them to be nonconnected clusters. This isomer favors the formation of homonuclear diatomic molecules and increases its stability in going down group III. For $\operatorname{In}_{2} \mathrm{~N}_{2}$, it is the lowest energy isomer. Although the analysis of the normal vibrational modes reveals an imaginary frequency, there is a real minimum (with no imaginary frequencies) with $C_{s}$ symmetry. Both the configurational parameters and the total energy of the $C_{s}$ configuration remain nearly the same with respect to those of the $C_{\infty v}$ configuration. In $\mathrm{In}_{2} \mathrm{~N}_{2}{ }^{-}$, the $\mathrm{In}-\mathrm{N}$ distance increases to 5.28 $\AA$ when an electron is added. It therefore can be considered to be a nonconnected cluster.

The lowest energy isomer for $\mathrm{Al}_{2} \mathrm{~N}_{2}$ is the rhombus configuration $D_{2 h}$ (isomer V), with $D_{\infty h}$ (isomer IV) being $0.10 \mathrm{eV}$ higher in energy. However, for $\mathrm{Ga}_{2} \mathrm{~N}_{2}$ and $\operatorname{In}_{2} \mathrm{~N}_{2}$, the rhombus and $\mathrm{M}-\mathrm{N}-\mathrm{N}-\mathrm{M}$ linear isomers are almost degenerate. In the case of $\mathrm{Ga}_{2} \mathrm{~N}_{2}$, isomer $\mathrm{V}$ is $0.01 \mathrm{eV}$ above isomer IV, whereas in $\mathrm{In}_{2} \mathrm{~N}_{2}$, isomer IV is $0.001 \mathrm{eV}$ above isomer $\mathrm{V}$. Therefore, the lowest-energy isomer is $D_{2 h}$ in $\mathrm{Al}_{2} \mathrm{~N}_{2}$ and $\operatorname{In}_{2} \mathrm{~N}_{2}$ but $D_{\infty h}$ in $\mathrm{Ga}_{2} \mathrm{~N}_{2}$. This fact points out a difference with the results presented in our previous work ${ }^{8}$ in which the difference in energy between isomer IV and isomer $\mathrm{V}$ for $\mathrm{Ga}_{2} \mathrm{~N}_{2}$ and $\mathrm{In}_{2} \mathrm{~N}_{2}$ was about $0.2 \mathrm{eV}$. The origin of this discrepancy can be found in the basis sets employed in our previous calculations. As we reported in the Introduction, the DMol program uses numerical basis sets obtained for the neutral atoms in vacuo. The numerical basis sets may not capture the changes in the electron density when moving from an atom to a molecule (or when several atoms are bonded to form a molecule).

When an electron is added to neutral $\mathrm{Al}_{2} \mathrm{~N}_{2}$, a change in the configurational symmetry is predicted. The anionic dimer with the $\mathrm{Al}-\mathrm{N}-\mathrm{N}-\mathrm{Al}$ structure belongs to the $D_{\infty h}$ symmetry point group. When comparing the $D_{2 h}$ neutral and negative isomer, the $\mathrm{Al}-\mathrm{N}$ distance decreases, but the $\mathrm{N}-\mathrm{N}$ bond length undergoes a larger increase. In the case of the $D_{\infty h}$ isomer, the $\mathrm{Al}-\mathrm{N}$ distance also decreases, but the $\mathrm{N}-\mathrm{N}$ distance increases very little. The molecular orbital description help us to understand this change. The LUMO (lowest unoccupied molecular orbital) in the neutral $D_{2 h}$ configuration contains an antibonding contribution for the $\mathrm{N}-\mathrm{N}$ interaction; therefore, an unstable situation occurs when $\mathrm{Al}_{2} \mathrm{~N}_{2}$ accepts an extra electron. However, the LUMO in the neutral $D_{\infty h}$ isomer contains a bonding contribution for the $\mathrm{Al}-\mathrm{N}$ interactions, with only a small amount of antibonding $\mathrm{N}-\mathrm{N}$ character. Similar changes in the point group symmetry and configurations are predicted in $\mathrm{In}_{2} \mathrm{~N}_{2}$ upon accepting an extra electron.

In $\mathrm{Ga}_{2} \mathrm{~N}_{2}$, the lowest-energy isomer for the anion presents a $\mathrm{Ga}-\mathrm{Ga}-\mathrm{N}-\mathrm{N}$ configuration with $C_{\infty v}$. This structure for the neutral dimer had been considered to be a nonconnected cluster due to the large $\mathrm{Ga}-\mathrm{N}$ distance (4.49 $\AA$ ). However, in the anionic cluster, the $\mathrm{Ga}-\mathrm{N}$ distance is significantly shortened to $1.99 \AA$. The $\mathrm{Ga}-\mathrm{N}$ bond length is now close to the diatomic GaN value of $1.87 \AA$. The N-N bond length is nearly constant
TABLE 3: Symmetry Labels and Frequencies $\left(\omega, \mathrm{cm}^{-1}\right)$ of the Normal Modes of Vibration for the Neutral and Anionic Dimers

\begin{tabular}{cccccc}
\hline mode & $\mathrm{Al}_{2} \mathrm{~N}_{2}-\mathrm{V}$ & mode & $\mathrm{Ga}_{2} \mathrm{~N}_{2}-\mathrm{IV}$ & mode & $\mathrm{In}_{2} \mathrm{~N}_{2}-\mathrm{V}$ \\
\hline$b_{3 \mathrm{u}}$ & 157 & $\pi_{\mathrm{g}}$ & 89 & $b_{2 \mathrm{u}}$ & 108 \\
$b_{2 \mathrm{u}}$ & 198 & $\sigma_{\mathrm{u}}$ & 193 & $a_{\mathrm{g}}$ & 115 \\
$a_{\mathrm{g}}$ & 327 & $\pi_{\mathrm{u}}$ & 383 & $b_{3 \mathrm{u}}$ & 117 \\
$b_{1 \mathrm{u}}$ & 562 & $\sigma_{\mathrm{g}}$ & 489 & $b_{1 \mathrm{u}}$ & 388 \\
$b_{3 \mathrm{~g}}$ & 571 & $\sigma_{\mathrm{u}}$ & 1739 & $b_{3 \mathrm{~g}}$ & 464 \\
$a_{\mathrm{g}}$ & 1397 & & & $a_{\mathrm{g}}$ & 1513 \\
\hline mode & $\mathrm{Al}_{2} \mathrm{~N}_{2}{ }^{-}-\mathrm{IV}$ & mode & $\mathrm{Ga}_{2} \mathrm{~N}_{2}{ }^{-}-\mathrm{III}$ & mode & $\mathrm{In}_{2} \mathrm{~N}_{2}{ }^{-}-\mathrm{IV}$ \\
\hline$\pi_{\mathrm{g}}$ & 107 & $\pi$ & 74 & $\pi_{\mathrm{g}}$ & 46 \\
$\pi_{\mathrm{u}}$ & 291 & $\sigma$ & 206 & $\sigma_{\mathrm{u}}$ & 87 \\
$\sigma_{\mathrm{u}}$ & 391 & $\pi$ & 316 & $\pi_{\mathrm{u}}$ & 217 \\
$\sigma_{\mathrm{g}}$ & 721 & $\sigma$ & 334 & $\sigma_{\mathrm{g}}$ & 350 \\
$\sigma_{\mathrm{u}}$ & 1592 & $\sigma$ & 1925 & $\sigma_{\mathrm{u}}$ & 1692
\end{tabular}

in going from the neutral to the anionic cluster, and the $\mathrm{Ga}-\mathrm{Ga}$ bond length decreases considerably from $2.68 \AA$ in the neutral dimer to $2.37 \AA$ in the anionic one. The $\mathrm{Ga}-\mathrm{Ga}$ distance is a little smaller than that in the $\mathrm{Ga}_{2}$ molecule (2.41 $\AA$ ). Analysis of the molecular orbitals finds a larger bonding-contribution center over the $\mathrm{Ga}-\mathrm{Ga}$ and $\mathrm{Ga}-\mathrm{N}$ interactions for the HOMO (highest occupied molecular orbital) of the anionic dimer. Thus, two molecules (i.e., $\mathrm{Ga}_{2}$ and $\mathrm{N}_{2}$ ) that are weakly bonded in the neutral charge state form a stronger bond upon accommodating an extra electron. The atomic and bonding property analysis, discussed in subsection III D, allows us to explain this change in the anionic state.

Table 3 gives the calculated vibrational frequencies for the neutral and anionic isomers with the lowest total energy. These isomers are the ones associated with the zero energy values in Table 2. First, we present the results for both the neutral and anionic aluminum and indium nitride dimers since they are found to be in the same configurational symmetry. Then, we present the results for the neutral and anionic $\mathrm{Ga}_{2} \mathrm{~N}_{2}$ clusters.

For neutral $\mathrm{Al}_{2} \mathrm{~N}_{2}$ and $\mathrm{In}_{2} \mathrm{~N}_{2}$, the lowest-frequency modes correspond to a bending out of the plane $\left(b_{3 \mathrm{u}}\right.$ and $\left.b_{2 \mathrm{u}}\right)$, and the highest frequency one $\left(a_{\mathrm{g}}\right)$ involves mainly the vibration of the $\mathrm{N}-\mathrm{N}$ bond. The value of this mode is greater in $\operatorname{In}_{2} \mathrm{~N}_{2}$ than in $\mathrm{Al}_{2} \mathrm{~N}_{2}$, which is in agreement with the distances for the $\mathrm{N}-\mathrm{N}$ bond in these dimers. The $b_{1 \mathrm{u}}$ and $b_{3 \mathrm{~g}}$ modes correspond to the stretching of $\mathrm{M}-\mathrm{N}$ bonds. For the anionic clusters, the first mode, $\pi_{\mathrm{g}}$, corresponds to the bending of the molecule into the plane, and the second mode, $\pi_{\mathrm{u}}$, displays the bending out of the plane. The $\sigma_{\mathrm{u}}$ and $\sigma_{\mathrm{g}}$ modes involve the asymmetric and symmetric stretching of $\mathrm{M}-\mathrm{N}$ bonds in the cluster, respectively. The last $\sigma_{\mathrm{u}}$ mode takes into account the vibration of the $\mathrm{N}-\mathrm{N}$ bond. In this way, the frequency values of the highest normal modes in the neutral and the anion are directly comparable because they involve the movement of the same type of bond. These values reflect the same behavior as that previously described using the criteria associated with the bond lengths.

The analysis of normal vibrational modes in neutral $\mathrm{Ga}_{2} \mathrm{~N}_{2}$ reflects behavior that is similar to what was described previously for the anionic aluminum and indium nitride since it belongs to same symmetry point group. However, we find the following differences in $\mathrm{Ga}_{2} \mathrm{~N}_{2}{ }^{-}: 1 \sigma$ involves the vibration of the $\mathrm{Ga}-\mathrm{Ga}$ bond, $2 \sigma$ reflects the stretching of the $\mathrm{Ga}-\mathrm{N}$, and $3 \sigma$ corresponds to the vibrational movement of the $\mathrm{N}-\mathrm{N}$ bond. It is important the frequency value of this last mode increases in going from the neutral to the anion, but the $\mathrm{N}-\mathrm{N}$ bond length does not change. The frequency value increases because the $\mathrm{N}-\mathrm{N}$ bond is not as strongly coupled in the anionic dimer as in the neutral one. 

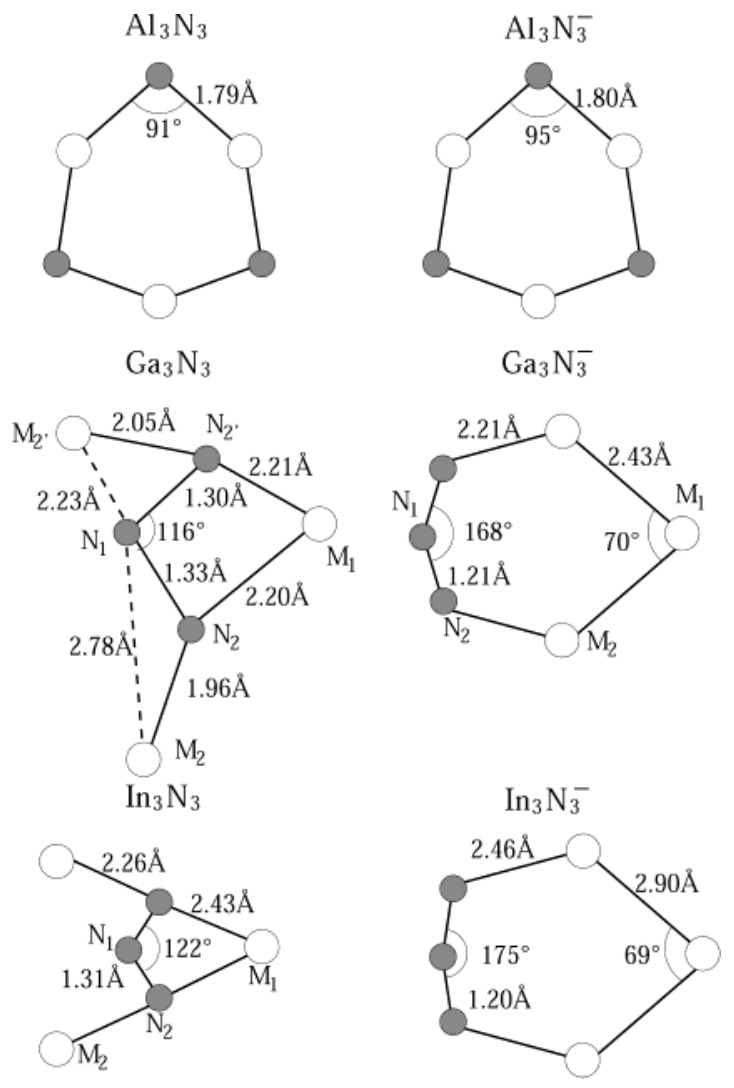

Figure 2. Structures of the lowest-energy isomers of the neutral and anionic trimers. The filled circles represent the nitrogen atoms, and the empty circles represent the metal atoms.

TABLE 4: Symmetry and Energies Relative to the Most Stable Isomer in Each Case for the Nitride Trimers

\begin{tabular}{lcccccc}
\hline & \multicolumn{5}{c}{$\Delta E(\mathrm{eV})$} \\
\cline { 2 - 7 } isomer & $\mathrm{Al}_{3} \mathrm{~N}_{3}$ & $\mathrm{Al}_{3} \mathrm{~N}_{3}{ }^{-}$ & $\mathrm{Ga}_{3} \mathrm{~N}_{3}$ & $\mathrm{Ga}_{3} \mathrm{~N}_{3}{ }^{-}$ & $\mathrm{In}_{3} \mathrm{~N}_{3}$ & $\mathrm{In}_{3} \mathrm{~N}_{3}{ }^{-}$ \\
\hline $\mathrm{A}-D_{3 h}$ & 0.00 & 0.00 & 2.27 & 1.27 & 5.07 & 4.14 \\
$\mathrm{~B}-C_{2 v}$ & 1.17 & 1.34 & 0.56 & 0.00 & 0.23 & 0.00 \\
$\mathrm{C}-C_{2 v}$ & 0.24 & 0.20 & 1.48 & 1.23 & 2.52 & 3.23 \\
$\mathrm{D}-C_{s}$ & 0.08 & 1.29 & 0.00 & 1.08 & 0.00 & 1.13
\end{tabular}

Recent experimental ${ }^{18,19}$ and theoretical ${ }^{20,22}$ studies performed on anionic dimers of $\mathrm{Al}_{2} \mathrm{P}_{2}$ and $\mathrm{Ga}_{2} \mathrm{P}_{2}$ and our previous work on $\mathrm{In}_{2} \mathrm{As}_{2}{ }^{31}$ revealed that the lowest-energy isomer for the anion has a butterfly configuration. In this work, we have computed this structure for all anionic nitride dimers. For the gallium and indium nitride dimers, we found that the metallic atoms located out of the plane prefer to move to a planar configuration during the optimization process. For $\mathrm{Al}_{2} \mathrm{~N}_{2}{ }^{-}$, the butterfly structure is a real minimum, but its energy is $1.50 \mathrm{eV}$ higher than that of the $D_{\infty h}$ isomer.

C. Structural and Vibrational Properties: Trimers. For total energy calculations on the nitride trimers, we chose only four isomeric configurations that are based on our previous work $^{9}$ (see Figure 1). Isomers A, B, and C represent planar configurations, and $\mathrm{D}$ isomer represents a $3 \mathrm{D}$ configuration. In Figure 2, we collected only the optimum values for the lowestenergy isomers in neutral and anionic clusters. The rest of the values have been omitted for the sake of brevity, but they are available from the authors upon request.

In Table 4, the relative energy values for each isomer with respect to the most stable one are collected. The results show that $\mathrm{Al}_{3} \mathrm{~N}_{3}$ exhibits a different trend in comparison to that of $\mathrm{Ga}_{3} \mathrm{~N}_{3}$ and $\mathrm{In}_{3} \mathrm{~N}_{3}$.
TABLE 5: Symmetry Labels and Frequencies $\left(\omega, \mathrm{cm}^{-1}\right)$ of the Normal Modes of Vibration for the Neutral and Anionic Trimers

\begin{tabular}{|c|c|c|c|c|c|}
\hline mode & $\mathrm{Al}_{3} \mathrm{~N}_{3}-\mathrm{A}$ & mode & $\mathrm{Ga}_{3} \mathrm{~N}_{3}-\mathrm{D}$ & mode & $\mathrm{In}_{3} \mathrm{~N}_{3}-\mathrm{D}$ \\
\hline$e^{\prime}$ & 170 & $a^{\prime}$ & 46 & $a_{1}$ & 33 \\
\hline$a_{2}^{\prime \prime}$ & 229 & $a^{\prime \prime}$ & 60 & $b_{1}$ & 47 \\
\hline$e^{\prime}$ & 284 & $a^{\prime}$ & 95 & $b_{2}$ & 61 \\
\hline$a_{1}^{\prime}$ & 456 & $a^{\prime \prime}$ & 132 & $a_{2}$ & 115 \\
\hline$a_{1}^{\prime \prime}$ & 634 & $a^{\prime}$ & 182 & $a_{1}$ & 141 \\
\hline$e^{\prime}$ & 662 & $a^{\prime}$ & 212 & $b_{2}$ & 146 \\
\hline$a_{2}^{\prime}$ & 857 & $a^{\prime \prime}$ & 315 & $b_{1}$ & 350 \\
\hline \multirow[t]{5}{*}{$e^{\prime}$} & 860 & $a^{\prime}$ & 400 & $a_{1}$ & 361 \\
\hline & & $a^{\prime}$ & 509 & $b_{2}$ & 426 \\
\hline & & $a^{\prime}$ & 906 & $a_{1}$ & 839 \\
\hline & & $a^{\prime}$ & 1185 & $a_{1}$ & 1148 \\
\hline & & $a^{\prime}$ & 1274 & $b_{2}$ & 1281 \\
\hline mode & $\mathrm{Al}_{3} \mathrm{~N}_{3}{ }^{-}-\mathrm{A}$ & mode & $\mathrm{Ga}_{3} \mathrm{~N}_{3}{ }^{-}-\mathrm{B}$ & mode & $\mathrm{In}_{3} \mathrm{~N}_{3}{ }^{-}-\mathrm{B}$ \\
\hline$e^{\prime \prime}$ & 186 & $b_{1}$ & 77 & $a_{1}$ & 65 \\
\hline$e^{\prime}$ & 230 & $a_{1}$ & 106 & $b_{1}$ & 67 \\
\hline$a_{1}^{\prime}$ & 233 & $b_{2}$ & 107 & $b_{2}$ & 81 \\
\hline$a_{1}^{\prime}$ & 414 & $a_{2}$ & 165 & $b_{2}$ & 122 \\
\hline$e^{\prime}$ & 617 & $b_{2}$ & 184 & $a_{1}$ & 135 \\
\hline$a_{1}^{\prime}$ & 619 & $a_{1}$ & 207 & $a_{2}$ & 139 \\
\hline$e^{\prime}$ & 822 & $b_{2}$ & 255 & $b_{2}$ & 231 \\
\hline \multirow[t]{5}{*}{$a_{2}^{\prime}$} & 828 & $a_{1}$ & 269 & $a_{1}$ & 234 \\
\hline & & $b_{1}$ & 545 & $b_{1}$ & 570 \\
\hline & & $a_{1}$ & 577 & $a_{1}$ & 602 \\
\hline & & $a_{1}$ & 1249 & $a_{1}$ & 1288 \\
\hline & & $b_{2}$ & 1997 & $b_{2}$ & 2038 \\
\hline
\end{tabular}

The lowest-energy isomer of $\mathrm{Al}_{3} \mathrm{~N}_{3}$ is the hexagonal configuration of $D_{3 h}$ symmetry (A isomer) for the neutral as well as the anionic cluster with alternate $\mathrm{Al}-\mathrm{N}$ bonds. The $\mathrm{Al}-\mathrm{N}$ bonds dominate the stability of the structure with nearly the same bond length as that in the monomer. The $\mathrm{D}$ isomer is almost degenerate in energy with the $\mathrm{A}$ isomer for the neutral aluminum nitride trimer, but this structure undergoes a larger increase in energy upon accommodating an extra electron.

The scenario for the gallium and indium nitride trimers is completely different: the $\mathrm{A}$ and $\mathrm{C}$ isomers are much higher in energy than the $\mathrm{B}$ and $\mathrm{D}$ isomers both in the neutral and anionic clusters. For the neutral trimers, the $\mathrm{D}$ isomer is the minimum, followed closely by the B isomer, whereas in the anionic trimers, the $\mathrm{B}$ isomer is the lowest one. Contrary to what was predicted in the DMol calculations, ${ }^{9}$ the D isomer is the most stable for $\mathrm{In}_{3} \mathrm{~N}_{3}$. The optimization of the $C_{S}$ structure ended with a planar geometry, corresponding to higher $\left(C_{2 v}\right)$ symmetry. However, a numerical problem arose: using the default grid to compute the density functional integrals in Gaussian 98, we found that the $b_{1}$ mode (movement up and down with respect to the plane of $\mathrm{In}_{1}$, which would lead back to the $C_{s}$ structure) appears to have an imaginary frequency. Within the $C_{s}$ structure, this mode corresponds to a totally symmetric representation $\left(a^{\prime}\right)$, hence it should always have a real frequency after optimization. Employing the ultrafine grid to calculate the numerical integrals, we have found that the $C_{2 v}$ structure displayed in Figure 2 is indeed the real minimum and that the $b_{1}$ frequency is really positive (see Table 5).

The results for the neutral gallium nitride trimer are also found to be different from the DMol results. ${ }^{9}$ Here, optimization of the $C_{s}$ structure shown in Figure 1 leads to $C_{2 v}$ planar geometry. As was the case in our previous work, ${ }^{9}$ this configuration has an imaginary frequency. Displacing the system along this normal coordinate and employing the ultrafine grid yielded in-plane deformation of the previous structure, and the real minimum with $C_{s}$ planar geometry shown in Figure 2 is predicted.

For the neutral and anionic gallium and indium nitride trimers, a preference for the structures with the $\mathrm{N}-\mathrm{N}-\mathrm{N}$ subunit is 
found. In the neutral trimers, this $\mathrm{N}-\mathrm{N}-\mathrm{N}$ subunit is angular. This is due to a higher coordination with the metallic atoms. The $\mathrm{M}-\mathrm{N}$ distances are in the range of the diatomic molecule, whereas the $\mathrm{N}-\mathrm{N}$ distance is between the distances associated with the double-bonded $\mathrm{N}_{2} \mathrm{H}_{2}(1.25 \AA)$ and the single-bonded $\mathrm{N}_{2} \mathrm{H}_{4}(1.50 \AA)$. However, in the anionic trimers, a larger opening of the bent angle in the $\mathrm{N}-\mathrm{N}-\mathrm{N}$ subunit along with a strong decrease in the $\mathrm{N}-\mathrm{N}$ distances being very similar to the linear azide ion value $(1.20 \AA)$ is predicted. Anionic trimers have $\mathrm{M}-\mathrm{N}$ bonds with a longer bond length than that in the neutral cases. In this way, the formation of $\mathrm{N}-\mathrm{N}$ multiple bonds is preferred. The atomic charges values that will be discussed in subsection III D also support these conclusions.

Because the neutral and anionic aluminum nitride trimers are isostructural, their vibrational modes are very similar. The addition of an electron produces a different relative ordering in those modes that are very close to each other (see Table 5). In both cases, the lowest-energy modes correspond to out-of-plane bending $\left(e^{\prime \prime}, a_{2}^{\prime \prime}\right)$, whereas the other modes are associated with in-plane bending $\left(e^{\prime}, e^{\prime}\right)$. The following vibrations produce breathing modes $\left(a_{1}^{\prime}, a_{1}^{\prime}\right)$; the first one is due to the symmetric stretching of all of the $\mathrm{Al}-\mathrm{N}$ bonds, and the second one is a bending mode opening the $\mathrm{Al}-\mathrm{N}-\mathrm{Al}$ angle. The atomic displacements of the highest-frequency $\operatorname{modes}\left(a_{2}^{\prime}, e^{\prime}\right)$ correspond to the asymmetric stretching of the $\mathrm{Al}-\mathrm{N}$ bonds that produces an aluminum ring torsion inside the nitrogen triangle.

Although $\mathrm{Ga}_{3} \mathrm{~N}_{3}$ and $\mathrm{In}_{3} \mathrm{~N}_{3}$ do not have the same symmetry, the atomic displacements are very similar since the $C_{s}$ structure for $\mathrm{Ga}_{3} \mathrm{~N}_{3}$ is an in-plane deformation of $C_{2 v}$ structure. In this sense, we describe the results for the neutral gallium and indium nitride trimers together. The frequency values are collected in Table 5. The four lowest modes correspond to the bending of atoms in and out of the plane. The next five modes involve the torsion and stretching of the metal-nitrogen bonds. In all of these modes, the $\mathrm{N}-\mathrm{N}-\mathrm{N}$ skeleton is moved as a rigid unit. However, the three highest frequencies involve the movement of this unit: the first one reflects the opening of the $\mathrm{N}-\mathrm{N}-\mathrm{N}$ angle, and the rest involve the symmetric and asymmetric stretching of the $\mathrm{N}-\mathrm{N}$ bonds.

The anionic gallium and indium nitride trimers show the same structure. As is the case with the neutral trimer, the first eight frequencies $\left(<300 \mathrm{~cm}^{-1}\right)$ correspond to the bending and torsion of the $\mathrm{M}-\mathrm{M}$ and $\mathrm{M}-\mathrm{N}$ bonds. When comparing the frequency values of these modes with the corresponding ones in the neutral trimers, an increase in their values is observed, which is associated with the corresponding decrease in the bond lengths, as noted previously. The last four higher modes are almost exclusively due to movements of the $\mathrm{N}_{3}{ }^{-}$subunit. The $b_{1}$ and $a_{1}$ frequencies are almost degenerate, corresponding to a bending of atoms in and out of the plane, respectively. A small splitting of these modes confirms that the coupling with the vibrations of the rest of the atoms is almost negligible. The average value is $561 \mathrm{~cm}^{-1}$ in $\mathrm{Ga}_{3} \mathrm{~N}_{3}{ }^{-}$and $586 \mathrm{~cm}^{-1}$ in $\mathrm{In}_{3} \mathrm{~N}_{3}{ }^{-}$. The last two frequencies reflect the symmetric and asymmetric stretching of $\mathrm{N}-\mathrm{N}$ bonds, respectively (1249 and $1997 \mathrm{~cm}^{-1}$ in $\mathrm{Ga}_{3} \mathrm{~N}_{3}{ }^{-}$and 1288 and $2038 \mathrm{~cm}^{-1}$ in $\mathrm{In}_{3} \mathrm{~N}_{3}^{-}$). These values are in very good agreement with the experimental results for the azide. The experimental value for the bending frequency ${ }^{32}$ is $640 \mathrm{~cm}^{-1}$, for the symmetric stretching ${ }^{33}$ is $1350 \mathrm{~cm}^{-1}$, and for the asymmetric stretching ${ }^{34}$ is $1986 \mathrm{~cm}^{-1}$ in the azide ion. It therefore can be concluded that the $\mathrm{N}-\mathrm{N}-\mathrm{N}$ subunit behaves as an azide ion in the anionic gallium and indium nitride trimers and it is the most important structural feature of these clusters. However, the $\mathrm{N}-\mathrm{N}-\mathrm{N}$ unit in the neutral clusters does not
TABLE 6: Topological Charges for Metal and Nitrogen Atoms in the Most-Stable Neutral and Anionic Isomers of the Monomers and Dimers ${ }^{a}$

Monomer

\begin{tabular}{|c|c|c|c|c|c|c|c|}
\hline & \multicolumn{2}{|c|}{$\mathrm{Q}_{\mathrm{M}}$} & $\mathrm{Q}_{\mathrm{N}}$ & & \multicolumn{2}{|c|}{$\mathrm{Q}_{\mathrm{M}}$} & $\mathrm{Q}_{\mathrm{N}}$ \\
\hline AlN & \multicolumn{2}{|c|}{0.935} & -0.935 & $\mathrm{AlN}^{-}$ & \multicolumn{2}{|c|}{0.444} & -1.444 \\
\hline $\mathrm{GaN}$ & \multicolumn{2}{|c|}{0.648} & -0.648 & $\mathrm{GaN}^{-}$ & \multicolumn{2}{|c|}{0.092} & -1.092 \\
\hline InN & \multicolumn{2}{|c|}{0.529} & -0.529 & $\mathrm{InN}^{-}$ & \multicolumn{2}{|c|}{-0.067} & -0.933 \\
\hline \multicolumn{8}{|c|}{ Dimer } \\
\hline & $\mathrm{Q}_{\mathrm{M}}$ & $\mathrm{Q}_{\mathrm{N}}$ & & $\mathrm{Q}_{\mathrm{M}_{1}}$ & $\mathrm{Q}_{\mathrm{M}_{2}}$ & $\mathrm{Q}_{\mathrm{N}_{1}}$ & $\mathrm{Q}_{\mathrm{N}_{2}}$ \\
\hline${ }_{2} \mathrm{~N}_{2}$ & 0.773 & -0.773 & $3 \quad \mathrm{Al}_{2} \mathrm{~N}_{2}{ }^{-}$ & 0.361 & & -0.860 & \\
\hline $\mathrm{Ga}_{2} \mathrm{~N}_{2}$ & 0.457 & -0.457 & $7 \mathrm{Ga}_{2} \mathrm{~N}_{2}^{-}$ & -0.219 & -0.224 & -0.440 & -0.120 \\
\hline $\mathrm{In}_{2} \mathrm{~N}_{2}$ & 0.465 & -0.465 & $5 \quad \mathrm{In}_{2} \mathrm{~N}_{2}^{-}$ & -0.063 & & -0.423 & \\
\hline
\end{tabular}

${ }^{a}$ Atoms are labelled according to Figure 2.

TABLE 7: Topological Charges for All of the Different Atoms by Symmetry in the Most-Stable Neutral and Anionic Isomers of the Trimers ${ }^{a}$

\begin{tabular}{lrrrrrr}
\multicolumn{7}{c}{ Trimers } \\
\hline & \multicolumn{1}{c}{$\mathrm{Q}_{\mathrm{M}_{1}}$} & $\mathrm{Q}_{\mathrm{N}_{1}}$ & $\mathrm{Q}_{\mathrm{M}_{2}}$ & $\mathrm{Q}_{\mathrm{M}_{2}^{\prime}}$ & $\mathrm{Q}_{\mathrm{N}_{2}}$ & $\mathrm{Q}_{\mathrm{N}_{2}^{\prime}}$ \\
\hline $\mathrm{Al}_{3} \mathrm{~N}_{3}$ & 2.075 & -2.075 & & & & \\
$\mathrm{Al}_{3} \mathrm{~N}_{3}{ }^{-}$ & 1.781 & -2.111 & & & & \\
$\mathrm{Ga}_{3} \mathrm{~N}_{3}$ & 0.590 & -0.237 & 0.600 & 0.577 & -0.839 & -0.690 \\
$\mathrm{Ga}_{3} \mathrm{~N}_{3}{ }^{-}$ & -0.214 & -0.171 & 0.013 & & -0.319 & \\
$\mathrm{In}_{3} \mathrm{~N}_{3}$ & 0.584 & -0.307 & 0.545 & & -0.684 & \\
$\mathrm{In}_{3} \mathrm{~N}_{3}{ }^{-}$ & -0.238 & -0.182 & 0.011 & & -0.296 &
\end{tabular}

${ }^{a}$ Atoms are labelled according to Figure 2.

behave as an azide ion, which can be seen in Table 5 . The cluster values are much smaller than the $\mathrm{N}_{3}{ }^{-}$experimental values. This fact is also in agreement with the bond-distance criteria employed previously.

D. Atomic and Bonding Properties. For the discussion of the character of the chemical bond and the effect on an added electron on the chemical bond in these clusters, we will use the AIM theory and its atomic charges. The topological atomic charges are independent of the molecular orbital description and are computed by the integration of the electron density over the atomic basin. ${ }^{28}$

We already have employed the AIM theory in the study of the chemical bond in the neutral monomers and dimers of the group III nitrides ${ }^{35}$ and in the analysis of the evolution of their chemical bonding in going from the molecules to the solid state. ${ }^{11}$ In our previous contributions, we showed that the $\mathrm{M}-\mathrm{N}$ bond represents a polar nonsharing interaction, the $\mathrm{M}-\mathrm{M}$ bond exhibits a nonpolar and nonsharing interaction, and the $\mathrm{N}-\mathrm{N}$ bond represents a nonpolar sharing contribution. These general features reported in our previous work are also found in this study for both the neutral and anionic clusters.

The topological charges for monomers and dimers are collected in Table 6 and for the trimers are listed in Table 7.

In the neutral monomers and dimers, we find only one noticeable difference with our previous results on $\mathrm{GaN}$. In $\mathrm{GaN}$, the charge transfer from the gallium atom to the nitrogen is $0.65 e$, which is $0.1 e$ higher than the previous result. ${ }^{35}$ The explanation of this fact is found in a larger difference in the bond length between the present calculations $(1.87 \AA)$ and the DMol calculation $(2.06 \AA$ ) because of the different electronic state. For $\mathrm{Ga}_{2} \mathrm{~N}_{2}$, the lowest-energy isomer belongs to the $D_{\infty h}$ group instead of the $D_{2 h}$ group of the DMol calculation. This structure also contains a nitrogen molecule, the only difference being that the gallium atoms join the $\mathrm{N}_{2}$ molecule along the $\mathrm{N}-\mathrm{N}$ axis instead of in the perpendicular direction. Thus, the topological charges are very similar to our previous results. In 
TABLE 8: Vertical and Adiabatic Values $(\mathrm{eV})$ of the Electron Affinity for the Monomers, Dimers, and Trimers

\begin{tabular}{llccc}
\hline & & monomer & dimer & trimer \\
\hline vertical EA & $(\mathrm{AlN})_{n}$ & 1.79 & 2.22 & 2.40 \\
adiabatic EA & & 1.72 & 1.26 & 2.31 \\
vertical EA & $(\mathrm{GaN})_{n}$ & 1.77 & 1.74 & 2.23 \\
adiabatic EA & & 1.64 & 1.27 & 1.60 \\
vertical EA & $(\mathrm{InN})_{n}$ & 1.33 & 0.99 & 2.26 \\
adiabatic EA & & 1.21 & 0.89 & 1.78
\end{tabular}

anionic monomers, the added electron is almost equally shared by two atoms $\left(\Delta Q_{\mathrm{N}}=-0.51 e,-0.44 e\right.$, and $-0.40 e$ for $\mathrm{AlN}$, $\mathrm{GaN}$, and InN, respectively, upon ionization). Even though the $\mathrm{Al}_{2} \mathrm{~N}_{2}{ }^{-}$and $\mathrm{In}_{2} \mathrm{~N}_{2}{ }^{-}$structures have $D_{\infty h}$ instead of $D_{2 h}$ symmetry, the $\mathrm{N}_{2}$ unit is again their most important feature, and they can be compared with the neutral $D_{2 h}$ structures. In doing so, we see that the extra electron is mainly located over the metallic atoms. In $\mathrm{Ga}_{2} \mathrm{~N}_{2}{ }^{-}$, the structural change is larger, leading to a $\mathrm{Ga}-\mathrm{Ga}-\mathrm{N}-\mathrm{N}$ linear isomer. The proximal nitrogen gets a charge transfer similar to that in the neutral case, but the distal nitrogen accepts a very small charge. Thus, the extra electron can be understood to be located mainly over two gallium atoms.

As we have showed in subsection III $\mathrm{C}$, the neutral and anionic $\mathrm{Al}_{3} \mathrm{~N}_{3}$ follow a different trend relative to that of the gallium and indium nitride trimers. In both cases, there is a larger charge transfer from aluminum to nitrogen. This transfer is around two electrons, thereby indicating that very high ionic character in the chemical bonds of these clusters is present. The added electron in an anionic cluster is mainly located over the aluminum atoms $\left(\Delta Q_{\mathrm{N}}=-0.036 e\right.$ and $\left.\Delta Q_{\mathrm{Al}}=-0.294 e\right)$.

In subsection III $\mathrm{C}$, we have shown that the neutral and anionic gallium and indium nitride trimers prefer structures with the $\mathrm{N}-\mathrm{N}-\mathrm{N}$ subunit. In the neutral gallium and indium nitrides, this subunit is angular, and computation of the topological charges allows us to state that the $\mathrm{N}-\mathrm{N}-\mathrm{N}$ is not an azide, as we have also pointed out using the distance criteria. There is a larger charge transfer from the metallic atoms to the nitrogen atoms. The total charge localized over the $\mathrm{N}-\mathrm{N}-\mathrm{N}$ subunit is $-1.77 e$ and $-1.68 e$ for $\mathrm{Ga}_{3} \mathrm{~N}_{3}$ and $\mathrm{In}_{3} \mathrm{~N}_{3}$, respectively. However, in the anionic clusters, because of the change in the structure, the $\mathrm{N}-\mathrm{N}-\mathrm{N}$ subunit is almost linear and is much more like the azide ion. The analysis of the topological charges reveals that the charge transfer from the metallic atoms to the nitrogens decreases, yielding charges of $-0.81 e$ and $-0.77 e$ in $\mathrm{Ga}_{3} \mathrm{~N}_{3}{ }^{-}$ and $\mathrm{In}_{3} \mathrm{~N}_{3}{ }^{-}$, respectively, located over the $\mathrm{N}-\mathrm{N}-\mathrm{N}$ subunit. This decrease in the charge transfer is a consequence of a smaller coordination index of the outer nitrogens in the anion trimers compared to the index for those in the neutral clusters.

We have also obtained the topological molecular graph, constructed by linking atoms that are endpoints of the topological bond paths. ${ }^{28}$ All of the structures presented the expected bond patterns - those used in Figures 1 and 2. This analysis also allowed us to prove that the structures of the neutral trimers of gallium and indium nitrides are the same (i.e., there are no bonds between $\mathrm{N}_{1}, \mathrm{M}_{2}$, and $\mathrm{M}_{2}^{\prime}$ (dashed lines in Figure 2)).

E. Electronic Properties. We have computed both adiabatic and vertical electron affinities for the monomers, dimers, and trimers of group III nitrides. The values are listed in Table 8. The definition of the electron affinity employed in this work is $\mathrm{EA}=E$ (neutral) $-E$ (anion). For all cases, the anion clusters are more stable than the neutral ones.

The values for the electron affinity computed for these compounds show the trend that is expected according to the evolution of the periodic properties. The electron affinity decreases in going down a group in the periodic table. Even though, we
TABLE 9: HOMO-LUMO Gap (eV) for the Most Stable Isomers in the Monomers, Dimers, and Trimers

\begin{tabular}{lccc}
\hline & monomer & dimer & trimer \\
\hline$(\mathrm{AlN})_{n}$ & 3.73 & 1.90 & 1.33 \\
$(\mathrm{AlN})_{n}{ }^{-}$ & 3.44 & 1.46 & 1.83 \\
$(\mathrm{GaN})_{n}$ & 3.68 & 1.69 & 1.65 \\
$(\mathrm{GaN})_{n}{ }^{-}$ & 3.42 & 0.88 & 1.56 \\
$(\mathrm{InN})_{n}$ & 2.68 & 1.31 & 1.74 \\
$(\mathrm{InN})_{n}{ }^{-}$ & 1.93 & 0.56 & 0.98
\end{tabular}

have computed the EA values for the stoichiometric clusters only up to size $n=3$, it is possible to appreciate the increase in its value with the cluster size to reach to bulk material value. ${ }^{16}$

We are aware of only two theoretical studies of the electron affinity in these compounds. Both of them have computed the adiabatic electron affinity for the AlN monomer, reporting values of $1.96 \mathrm{eV}^{15}$ and $1.91 \mathrm{eV} .^{30}$ These values are in reasonable agreement with our result. For the remaining clusters, because of the lack of experimental and theoretical studies, we compare the calculated values with the results reported for AlP, GaP, and InP. The adiabatic EA in (AlP $)_{n}$ with $n=2,3$ is measured to be about 2.15 and $2.45 \mathrm{eV},{ }^{18}$ whereas the theoretical value for the dimer is predicted to be $1.93 \mathrm{eV} .{ }^{20}$ For $(\mathrm{GaP})_{n}$ with $n=$ $1,2,3$, the adiabatic EA values from photoelectron spectroscopy are $1.96,1.86$, and $2.50 \mathrm{eV}$, respectively. ${ }^{16}$ Archibong et al., employing different theoretical methodologies, reported adiabatic EA values of $1.85-2.03 \mathrm{eV}$ for the $\mathrm{GaP}$ monomer and about $1.62 \mathrm{eV}$ for the $\mathrm{GaP}$ dimer. ${ }^{21}$ The experimental results for the adiabatic ${ }^{17}$ and vertical (in parentheses) ${ }^{36}$ electron affinity from photoelectron spectroscopy measurements of $(\mathrm{InP})_{n}$ are about 1.95 (1.88), 1.68 (1.75), and 1.30 (1.40) eV. In accordance with the evolution of the periodic properties, we should expect to find the EA values for the group III phosphide clusters to be smaller than the respective values in the group III nitride. However, our results showed the opposite trend, which may be due to fact that the nitrogens atoms do not accept the electron in the anionic state. Moreover, in gallium and indium anionic nitride trimers, even the nitrogen atoms transfer charge to the metallic atoms with respect to the charge of the neutral atoms. However, the phosphide compounds show less polar bonding (the difference in the electronegativity between the metallic atoms and phosphorus is smaller than those in the group III nitrides) than the nitrides compounds. The extra electron in the phosphide clusters is likely to be shared equally between all atoms in the cluster. The latter behavior was found in the negatively charged clusters of InAs. ${ }^{31}$

The HOMO-LUMO gaps have been computed for the most-stable isomers in the group III nitrides and are listed in Table 9.

As a general trend, we can observe a decrease in the gap values when the cluster size increases for both neutral and anionic clusters. Since these values should reach the bulk value with the increase in size of the cluster, subunits such as $\mathrm{N}_{2}$ and $\mathrm{N}_{3}$ with delocalized electrons are likely to be replaced by bulklike subunits. We have estimated the band gap energy for AlN and GaN using the same molecular basis sets and employing a Crystal 98 code. ${ }^{37}$ (The basis set of $\mathrm{InN}$ needs to be optimized to describe the solid properly.) The estimated values are 4.42 and $3.50 \mathrm{eV}$, respectively. ${ }^{38}$ These values are higher than those in Table 9, showing that these clusters are still far away from representing the bulk behavior.

\section{Conclusions}

The addition of an electron to each of the the neutral nitride clusters induces significant structural changes, the only exception 
being $\mathrm{Al}_{3} \mathrm{~N}_{3}$. The extra electron is located over the metallic atoms instead of being shared by all of the atoms in the cluster. The $\mathrm{N}_{2}$ and $\mathrm{N}_{3}$ subunits are the most important features in the anionic clusters, as they were in the neutral ones. Again, the exception is $\mathrm{Al}_{3} \mathrm{~N}_{3}$, which shows a preference for bulklike alternate bonds. By employing the atoms in molecules analysis, we found that the $\mathrm{M}-\mathrm{M}$ bond is nonpolar and has a nonsharing interaction, the $\mathrm{M}-\mathrm{N}$ bond is polar and has a nonsharing interaction, and the $\mathrm{N}-\mathrm{N}$ bond has a sharing interaction. The atomic charges indicate that the clusters have partial ionic character that decreases in going from $(\mathrm{AlN})_{n}$ to $(\mathrm{GaN})_{n}$ to $(\mathrm{InN})_{n}$. A smaller value of the electron affinity in these clusters is due to the localization of the electron over only the metallic atoms. The nitride clusters considered in this study have a HOMO-LUMO gap that is mainly controlled by the cluster configuration.

Acknowledgment. A.C. wishes to thank the Spanish Secretaría de Estado de Universidades, Investigación y Desarrollo and the Consejería de Educación y Cultura del Principado de Asturias for support during her foreign stay. Funding from the Spanish DGICyT, grant BQU2000-0466, is also acknowledged. We thank A. K. Kandalam and M. A. Blanco for fruitful discussions and for their careful reading of the manuscript.

\section{References and Notes}

(1) Costales, A.; Kandalam, A. K.; Franco, R.; Pandey, R. J. Phys. Chem. B 2002, 106, 1940-1944.

(2) Nakamura, S. In Proceedings of the International Symposium on Blue Laser and Light Emitting Diodes; Yoshikawa, A., Kishino, K., Kobayashi, M., Yasuda, T., Eds.; Chiba University Press: Japan, 1996; p 119.

(3) BelBruno, J. J. Chem. Phys. Lett. 1999, 313, 795

(4) BelBruno, J. J. Heteroat. Chem. 2000, 11, 281.

(5) Boo, B. H.; Liu, Z. J. Phys. Chem. A 1999, 103, 1250-1254

(6) Wu, H.; Zhang, C.; Xu, X.; Zheng, L.; Zhang, Q. Sci. China 2000, 43, 634-642.

(7) Andrews, L.; Zhou, M.; Chertihin, G. V.; Bare, W. J.; Hannachi, Y. J. Phys. Chem. A 2000, 104, 1656.

(8) Kandalam, A. K.; Pandey, R.; Blanco, M. A.; Costales, A.; Recio,

J. M.; Newsam, J. M. J. Phys. Chem. B 2000, 104, 4361.

(9) Kandalam, A. K.; Blanco, M. A.; Pandey, R. J. Phys. Chem. B 2001, 105, 6080 .

(10) Kandalam, A. K.; Blanco, M. A.; Pandey, R. J. Phys. Chem. B 2002, 106, 1945-1953.

(11) Costales, A.; Blanco, M. A.; Pendás, A. M.; Kandalam, A. K.; Pandey, R. J. Am. Chem. Soc. 2002, 124, 4116.

(12) Chang, C.; Patzer, A. B. C.; Sedlmayr, E.; Steinke, T.; Sülzle, D. Chem. Phys. Lett. 2001, 271, 283-292.

(13) Zhou, M.; Andrews, L. J. Phys. Chem. A 2000, 104, 1648-1655.

(14) Meloni, G.; Gingerich, K. A. J. Chem. Phys. 2000, 113, 10978.

(15) Leskiw, B. D.; Castleman, A. W., Jr.; Ashman, C.; Khanna, S. N. J. Chem. Phys. 2001, 114, 1165-1169.
(16) Taylor, T. R.; Asmis, K. R.; Xu, C.; Neumark, D. M. Chem. Phys. Lett. 1998, 297, 133.

(17) Asmis, K. R.; Taylor, T. R.; Neumark, D. M. Chem Phys. Lett. 1999, 308, 347.

(18) Gómez, H.; Taylor, T. R.; Neumark, D. M. J. Phys. Chem. A 2001, $105,6886-6893$.

(19) Taylor, T. R.; Gómez, H.; Asmis, K. R.; Neumark, D. M. J. Chem. Phys. 2001, 115, 4620-4631.

(20) Archibong, E. F.; Gregorius, R. M.; Alexander, S. A. Chem. Phys. Lett. 2000, 321, 253-261.

(21) Archibong, E. F.; St-Amant, A. Chem. Phys. Lett. 2000, 330, 199206.

(22) Archibong, E. F.; St-Amant, A. Chem. Phys. Lett. 2000, 316, 151159.

(23) DMol users' guide, version 2.3.6. Molecular Simulations, Inc.: San Diego, California, 1999.

(24) Frisch, M. J.; Trucks, G. W.; Schlegel, H. B.; Scuseria, G. E.; Robb, M. A.; Cheeseman, J. R.; Zakrzewski, V. G.; Montgomery, J. A., Jr.; Stratmann, R. E.; Burant, J. C.; Dapprich, S.; Millam, J. M.; Daniels, A. D.; Kudin, K. N.; Strain, M. C.; Farkas, O.; Tomasi, J.; Barone, V.; Cossi, M.; Cammi, R.; Mennucci, B.; Pomelli, C.; Adamo, C.; Clifford, S.; Ochterski, J.; Petersson, G. A.; Ayala, P. Y.; Cui, Q.; Morokuma, K.; Malick, D. K.; Rabuck, A. D.; Raghavachari, K.; Foresman, J. B.; Cioslowski, J.; Ortiz, J. V.; Stefanov, B. B.; Liu, G.; Liashenko, A.; Piskorz, P.; Komaromi, I.; Gomperts, R.; Martin, R. L.; Fox, D. J.; Keith, T.; Al-Laham, M. A. Peng, C. Y.; Nanayakkara, A.; Gonzalez, C.; Challacombe, M.; Gill, P. M. W.; Johnson, B. G.; Chen, W.; Wong, M. W.; Andres, J. L.; Head-Gordon, M.; Replogle, E. S.; Pople, J. A. Gaussian 98; Gaussian, Inc.: Pittsburgh, PA, 1998.

(25) Becke, A. D. Phys. Rev. A 1988, 38, 3098.

(26) Perdew, J. P.; Wang, Y. Phys. Rev. B 1992, 45, 13244

(27) Extensible Computational Chemistry Environment Basis Set Database, version 1.0. Molecular Science Computing Facility E., Laboratory, M. S.; Pacific Northwest Laboratory: Richland, WA, 1999.

(28) Bader, R. F. W. Atoms in Molecules; Oxford University Press: Oxford, U.K. 1990

(29) AIMPAC 95 Package. Keith, T. A.; Laidig, K. E.; Krug, P.; Cheeseman, J. R.; Bone, R. G. A.; Biegler-König, F. W.; Duke, J. A.; Tang, T.; Bader, R. F. W.; McMaster University, Canada. The code is available upon request. To contact the authors through e-mail: bader@mcmail.cis. mcmaster.ca.

(30) Gutsev, G. L.; Jena, P.; Bartlett, R. J. J. Chem. Phys. 1999, 110 2928-2935.

(31) Costales, A.; Pandey, R. Chem. Phys. Lett. 2002, 362, 210-216.

(32) Lamoreaux, R. T.; Dows, D. A. Spectrochim. Acta, Part A 1975, 31,1945 .

(33) Jackson, R. L.; Pellerite, M. J.; Brauman, J. I. J. Am. Chem. Soc. 1981, 103, 1802-1805.

(34) Polak, M.; Gruebele, M.; Saykally, R. J. J. Am. Chem. Soc. 1987, 109, 2884-2887.

(35) Costales, A.; Kandalam, A. K.; Pendás, A. M.; Blanco, M. A.; Recio, J. M.; Pandey, R. J. Phys. Chem. B 2000, 104, 4368.

(36) Xu, C.; de Beer, E.; Arnold, D. W.; Arnold, C. C.; Neumark, D. M. J. Chem. Phys. 1994, 101, 5406.

(37) Crystal98 users' manual. Saunders, V. R.; Dovesi, R.; Roetti, C.; Causà, M.; Harrison, N. M.; Orlando, R.; Zicovich-Wilson, C. M.; University of Torino, Italy, 1998.

(38) Jiang, H. Private communication, 2002. 